\title{
INFLUÊNCIA DA ADIÇÃO DA FÉCULA DE BATATA-DOCE (Ipomoea batatas L.) SOBRE A VISCOSIDADE DO PERMEADO DE SORO DE GUEIJO ${ }^{1}$
}

\author{
Rafael Leite Pinto de ANDRADE ${ }^{2, *}$, José Francisco Pereira MARTINS ${ }^{3}$
}

\section{RESUMO}

A viscosidade é um parâmetro importante na aceitabilidade de bebidas lácteas. O presente trabalho teve como objetivo principal fornecer dados relativos ao comportamento da viscosidade uma base de permeado de soro de queijo adicionada de fécula de batatadoce, dados que poderão ser utilizados na elaboração de uma nova bebida láctea. A fécula de batata-doce utilizada apresentou um grau de gelatinização de $72,64 \%$, umidade média de $7,88 \%$ e a seguinte composição centesimal média em base seca: $82,59 \%$ de amido, $9,33 \%$ de fibras dietéticas totais, $4,90 \%$ de proteínas, $2,08 \%$ de cinzas e 1,11\% de lipídios. O permeado de soro foi adicionado a três diferentes concentrações de fécula e submetido a diferentes tratamentos térmicos. A viscosidade mais adequada, em função dos dados obtidos junto aos produtos comerciais, estaria no intervalo de $45 \mathrm{mPa}$.s a $70 \mathrm{mPa}$.s. Assim sendo, a porcentagem de $6 \%$ de fécula de batata-doce e um tratamento térmico de $90^{\circ} \mathrm{C}$ por cerca de 5 minutos mostrou-se ser o mais adequado. O fluido obtido apresentou um comportamento pseudoplástico.

Palavras-chave: fécula; batata-doce; reologia; soro de queijo; bebida láctea; permeado.

\section{SUMMARY}

INFLUENCE OF SWEET POTATO STARCH AT PERMEATE WHEY VISCOSITY. Viscosity is an important parameter of milky drinks acceptability. This work supply data of the viscosity properties of permeate whey plus sweet potato starch basis; these data will may be used at development of a new milky beverage. The used sweet potato starch presented $72.64 \%$ of gelatinization, $7.88 \%$ of humidity and the following dry composition: $82.59 \%$ starch, $9.33 \%$ total dietary fibres, $4.90 \%$ proteins, $2.08 \%$ ashes and $1.10 \%$ lipids. The permeate whey had mixed at three different percentages of potato starch and had submitted at various thermal treatments. The most appropriate viscosity, in accord of commercial products, it would be in the interval of $45 \mathrm{mPa}$.s to $70 \mathrm{mPa}$.s. Therefore, the percentage of $6 \%$ of sweet potato starch and a thermal treatment of $90^{\circ} \mathrm{C}$ for about 5 minutes it was shown to be the most appropriate. The fluid presented a pseudoplastic properties.

Keywords: starch; sweet potato; reology; whey permeate.

\section{1 - INTRODUÇÃO}

O soro de queijo é um liquido opaco, amareloesverdeado, que contém cerca de $55 \%$ dos sólidos existentes no leite integral original [11] e representa cerca de 80 a $90 \%$ do volume de leite utilizado na fabricação de queijo [13, 19]. Possui uma DBO (Demanda Bioquímica de Oxigênio) entre 30.000 a $60.000 \mathrm{mg}$ de $\mathrm{O}_{2} / \mathrm{L}$, dependendo do processo utilizado na elaboração do queijo. Em média, cada tonelada de soro não tratado despejado por dia no sistema de tratamento de esgoto equivale a poluição diária de cerca de 470 pessoas [23]. No Brasil, o volume estimado de queijo produzido em 1997 foi de 415.000 toneladas [9], o que corresponde a produção de aproximadamente 3.320.000 toneladas de soro.

As aplicações do soro são inúmeras, englobando as indústrias de lácteos, carnes, misturas secas (para condimentar), panificação, chocolate, aperitivos e bebidas, entre outras. Ainda assim, apenas cerca de 50\% do soro produzido nos Estados Unidos e na Europa são utilizados na formulação de produtos, o restante é tratado como despejo [22].

Métodos como a ultrafiltração têm sido utilizados para separar as proteinas, os componentes mais "no-

1. Recebido para publicação em 06/02/2001. Aceito para publicação em 23/03/2002.

2. Fundação de Apoio à Pesquisa-FAP/DF. SQS 408 Bloco O Apto. 101. CEP 70257-150,DF.E-mail: andraderafael@hotmail.com

3. UFRRJ - DTA/IT/UFRRJ. Antiga Rod. Rio-SP, Km 47. E-mail: jfmarti@bbsup.com.br

* A quem a correspondência deve ser enviada. bres" do soro, dos outros constituintes (lactose e minerais) [21]. Durante o processo de ultrafiltração, originamse dois produtos: o concentrado ou retentado, representado pelo material que é retido pela membrana, e o permeado, denominação dada ao material que passa através da membrana.

Apesar de haver um mercado em expansão para os concentrados protéicos de soro, o soro desproteínado, que contém cerca de $90 \%$ dos sólidos totais e da DBO do soro original $[12,16]$, continua sendo um subproduto poluente que não pode ser tratado ou descartado simplesmente como esgoto sem gastos, devido a sua elevada demanda química de oxigênio (DQO) em torno de $50.000 \mathrm{mg}$ de $\mathrm{O}_{2} / \mathrm{L}$ de permeado [14, 17].

O permeado resultante da ultrafiltração pode ser utilizado de inúmeras maneiras, inclusive como substrato para elaboração de bebidas lácteas através da fermentação. Neste caso, a sua viscosidade é de grande importância para a aceitabilidade do produto final. Quando comparado às bebidas lácteas disponiveis no mercado, o permeado apresenta uma viscosidade baixa, que não se altera significantemente durante o processo fermentativo. Deste modo, a adição de um agente espessante é indicada para a elaboração do produto em questão.

Por várias razões a fécula de batata-doce pode ser utilizada como espessante: é um vegetal que possui larga adaptabilidade e alta produtividade mesmo em situações adversas de clima e solo [5]; apresenta grande quantidade de amido gelatinizável que pode atuar também como estabilizante; os carotenóides presentes po- 
dem fornecer uma coloração natural; é capaz de melhorar o substrato para os microrganismos responsáveis pela fermentação [7]. Em 1992, o Brasil produziu cerca de 603 mil toneladas de raizes, com um rendimento médio de 10t/ha, sendo o Rio Grande do Sul o maior produtor [15].

Os grânulos de amido, quando hidratados e aquecidos a temperatura suficiente, sofrem um processo irreversivel chamado de gelatinização. Durante este processo pode-se observar modificações acentuadas na solubilidade e propriedades mecânicas do amido, como um aumento na viscosidade da solução [4].

Os fluidos podem ser classificados em newtonianos ou não-newtonianos. Fluidos newtonianos são aqueles em que a tensão de cisalhamento $\left(\tau_{\mathrm{xy}}\right)$ é diretamente proporcional à taxa de deformação $(d u / d y)$, o que não ocorre com os fluidos não-newtonianos. Numerosas equações empíricas têm sido propostas para elaborar o modelo matemático das relações observadas entre a tensão de cisalhamento e a taxa de deformação para fluidos independentes do tempo. Elas podem ser adequadamente representadas, para muitas aplicações da engenharia pelo modelo exponencial, que para o escoamento unidimensional pode ser escrita genericamente como:

$\tau_{y x}=k\left(\frac{d u}{d y}\right)^{n}$

onde o expoente, $n$, é chamado de indice de comportamento do escoamento e $k$, de indice de consistência. Esta equação se reduz à lei de Newton para fluidos que apresentam comportamento newtoniano, onde $n=1$ e $k=\mu$ (viscosidade absoluta) [8].

Os fluidos em que a viscosidade aparente diminui com taxas de deformação crescentes $(n<1)$ são chamados pseudoplásticos (adelgaçam-se com as tensões tangenciais). A maioria dos alimentos pode ser enquadrada nesta categoria.

O presente artigo teve como objetivo principal fornecer dados relativos ao comportamento da viscosidade numa base de permeado de soro de queijo adicionada de fécula de batata-doce, dados estes que, futuramente, poderão ser utilizados como subsídios para elaboração de uma nova bebida láctea.

\section{2 - MATERIAIS E MÉTODOS}

\section{1 - Obtenção da fécula de batata-doce}

Para elaboração da fécula, foi utilizada a cultivar 'Rosinha do verdum' obtida junto ao campo experimental da EMBRAPA. O método de obtenção da fécula foi o proposto por VIEIRA et al. [20], que consiste em lavar as batatas, imergi-las por 15 minutos em água clorada, fragmentar em pedaços de aproximadamente $7 \mathrm{~cm}$ de comprimento e $3 \mathrm{~cm}$ de largura e imediatamente imergir em água em ebulição por cerca de 30 minutos. Após o cozimento, as batatas foram transferidas para uma despolpadeira onde ocorreu a remoção parcial da casca, o 'purê' obtido foi espalhado sobre peneiras de aço inox e levado a uma câmara de secagem a $60^{\circ} \mathrm{C}$ com circulação de ar até que alcançasse uma umidade em torno de $6 \%$. O 'purê' seco foi moído até uma granulometria em torno de $100 \mathrm{mesh}$. A fécula obtida foi acondicionada em potes de vidro bem vedados.

A fécula foi produzida nas dependências do Departamento de Tecnologia de Alimentos da UFRRJ, excetuando-se a etapa de moagem, realizada nas instalações do Centro de Tecnologia de Alimentos (CTAA), utilizando um moinho de faca e martelo TREU com peneira de $0,8 \mathrm{~mm} / \mathrm{mm}$.

\section{2 - Composição centesimal da fécula de batata-doce}

As análises relativas à composição centesimal da fécula de batata-doce foram realizadas no Departamento de Ciência e Tecnologia de Alimentos da Universidade Federal de Santa Catarina, no Laboratório de Ciência e Tecnologia de Cereais, de acordo com os respectivos métodos da AOAC [2]: umidade, método n. 925.10; lipídios métodos n. 920.85 e 920.39; cinzas método n. 923.03; e pelos seguintes métodos da AACC [1]: fibra dietética total, solúvel e insolúvel método n. 991.43; bglucanas método n. 995.16; proteinas método n. 46-12 $(\mathrm{N} \mathrm{x} \mathrm{6,25).}$

\section{3 - Análise do grau de gelatinização da fécula de batata-doce}

O método utilizado para determinação do grau de gelatinização foi o proposto por GURAYA \& TOLEDO [10]. O método consiste em traçar um paralelo entre a leitura espectofotométrica e o grau de gelatinização da amostra com base em uma curva padrão.

Para realização da curva padrão foram necessários a obtenção de amostras de amido de batata-doce gelatinizadas a 0\% e 100\%. Para obtenção do amido 0\% gelatinizado realizou-se a sua extração a frio segundo o roteiro do manual de práticas de químicas de alimentos de BOBBIO \& BOBBIO [3]. Para obtenção da amostra $100 \%$ gelatinizada, foram realizados os mesmos procedimentos utilizados na fabricação da fécula porém, utilizando um tratamento térmico mais intenso de modo a garantir que, teoricamente, todo o amido se encontraria gelatinizado.

\section{4 - Obtenção do soro e do permeado}

O processo de ultrafiltração foi realizado nas instalações do Instituto de Laticínios Cândido Tostes, utilizando soro proveniente da produção de queijo tipo 'Minas' por coagulação enzimática. A ultrafiltração do soro foi realizada em módulo de membranas tipo "hollow fiber" à temperatura ambiente. O permeado assim obtido, apresentou uma acidez titulável de 0,08\% (em ác. láctico) e foi estocado em recipientes plásticos de alta densidade, à temperatura de $-18^{\circ} \mathrm{C}$. 


\section{5 - Composição centesimal do permeado de soro de queijo}

As análises relativas à composição centesimal do permeado foram realizadas no Departamento de Tecnologia de Alimentos da Universidade Federal Rural do Rio de Janeiro. A análise de cinzas foi realizada em triplicata, pesando-se cerca de $10 \mathrm{~mL}$ da amostra que sofreu uma evaporação inicial em uma chapa aquecida e, em seguida foi incinerada a $550^{\circ} \mathrm{C}$ em mufla por cerca de 5 horas. Após resfriamento em dessecador, a amostra foi novamente pesada e a porcentagem de cinzas obtida por diferença.

O teor da lactose foi realizado em quadruplicata utilizando-se o método da Cloramina $\mathrm{T}$ de acordo com da SILVA et al. [18].

A determinação do extrato seco total foi realizada em triplicata, através da evaporação da fração líquida de $10 \mathrm{~mL}$ da amostra, em estufa a $105^{\circ} \mathrm{C}$ até alcançar peso constante.

Os valores encontrados para os demais constituintes do permeado, foram obtidos com base na literatura e através de diferença.

\section{6 - Estudo da viscosidade}

As análises relativas à viscosidade foram realizadas na EMBRAPA/CTAA utilizando-se o reômetro CONTRAVES modelo RHEOMAT 30, acoplado ao programador RHEOSCAN 100, com banho termostático RHEOTHERM 115 e registrador gráfico RIKADENKI. Os sistemas de medição utilizados foram DIN 14 e DIN 45 e a temperatura de análise foi de $8^{\circ} \mathrm{C}$. O RHEOSCAN 100 foi programado para elevar a rotação de 0 até 350rpm de forma constante em 4 minutos, e em seguida retornar a Orpm no mesmo intervalo de tempo.

O tratamento térmico, durante a preparação do substrato, possui dois propósitos: a dissolução do amido prégelatinizado, com conseqüente aumento da viscosidade, e a pasteurização do substrato.

O permeado foi aquecido até $90^{\circ} \mathrm{C}$, em seguida, com o auxilio de um liquidificador, por 2 minutos, foram desenvolvidas 3 amostras com as seguintes proporções de fécula: 5, 6, e $7 \%$. Com as amostras mantidas a $90^{\circ} \mathrm{C}$, foram retirados $150 \mathrm{~mL}$ de cada uma nos tempos $0,2,5$, $10,15,20$ e 30 minutos. As amostras retiradas eram imediatamente imersas em banho de gelo e seguiam para o teste de viscosidade.

Foram analisados alguns produtos comerciais (iogurte 'natural' de pote, bebidas lácteas fermentadas, probiótico, iogurte liquido) adquiridos no comércio a fim de serem utilizados como parâmetros de comparação.

\section{3 - RESULTADOS E DISCUSSÃO}

\section{1 - Composição centesimal da fécula de batata-doce}

Não é possivel realizar comparações rígidas dos valores obtidos, que se encontram na Tabela 1 , com os encontrados na literatura pois, além da grande variação entre as cultivares, há também diferenças no processamento para obtenção da fécula. Porém, em trabalho com féculas provenientes de 44 genótipos [6], foi encontrada uma média (em base seca) de: $83 \%$ de carboidratos, 3,9\% de proteína, $0,60 \%$ de lipídios, 1,89\% de cinzas e 10,3\% de fibras totais. O amido é um dos componentes que sofre maiores variações, em função da maturidade ou armazenamento [5].

O baixo teor de lipídios da fécula facilitou sua dissolução no permeado e contribuiu para o baixo valor calórico do produto final.

Pode-se verificar um teor relativamente elevado de fibra dietética total, provavelmente advindo da casca devido ao processo utilizado na elaboração da fécula.

TABELA 1. Composição da fécula de batata-doce.

\begin{tabular}{lccccccccc}
\hline & umidade & Lipídios* & proteínas* & cinzas* & F.D.T.* & AMIDO* & FDI* & FDS* \\
\hline Média & 7,88 & 1,11 & 4,90 & 2,08 & 9,33 & 82,59 & 6,13 & 3,20 \\
Erro padrão & 0,05 & 0,03 & 0,02 & 0,02 & 0,07 & 0,11 & 0,09 & 0,05 \\
Desvio padrão & 0,10 & 0,06 & 0,05 & 0,04 & 0,11 & 0,19 & 0,16 & 0,08 \\
\hline
\end{tabular}

* em base seca

Não foi detectada a presença de b-glucanas

\section{2 - Grau de gelatinização da fécula}

Como a amostra apresentou um peso de 0,20g e possui cerca de $82,59 \%$ de amido, o resultado obtido na Figura 1 de 0,12g de amido gelatinizado na amostra, significou que a amostra apresentou, na verdade, cerca de $72,64 \%$ de amido gelatinizado.

Deve-se salientar que, excluindo-se as fibras, todo carboidrato restante corresponderia a amido gelatinizável.

Analisando o grau de gelatinização obtido, pode-se concluir que o tratamento térmico utilizado durante o processo de elaboração da fécula foi adequado no que concerne a obtenção de uma fécula com boas características de solubilidade e potencial para utilização no rápido incremento da viscosidade do produto possibilitando, assim, um menor tempo de tratamento térmico.

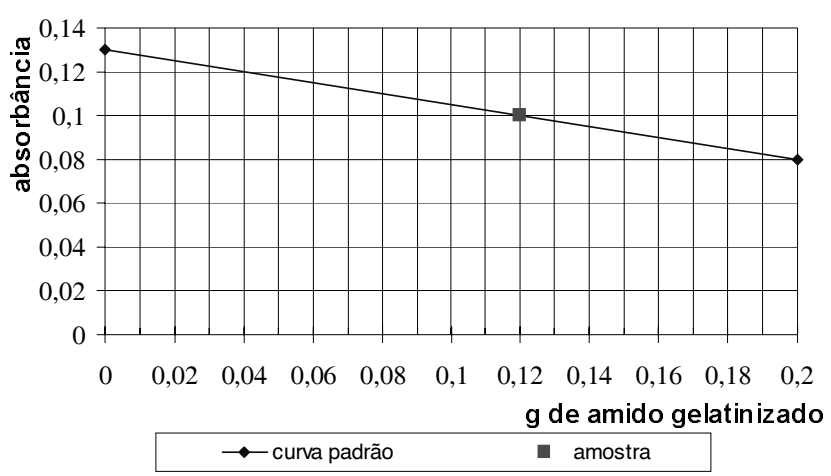

FIGURA 1. Curva padrão de absorbância X g de amido gelatinizado. 


\section{3 - Composição centesimal do permeado de soro de queijo}

Na Tabela 2 podemos verificar os resultados da análise de composição centesimal do permeado de soro de queijo utilizado no experimento.

TABELA 2. Composição centesimal* do permeado de soro de queijo.

\begin{tabular}{ccccc}
\hline Lactose (\%) & Cinzas (\%) & Ác. Láctico (\%) & Proteína (\%) & Gordura (\%) \\
\hline $\mathbf{8 4 , 0 4}$ & $\mathbf{1 0 , 5 4}$ & $\mathbf{4 , 8 2}$ & $\mathbf{0 , 5 0 - 1 , 0 0}$ & $<0,1$ \\
\hline
\end{tabular}

* em base seca

\section{4 - Viscosidade}

Analisando a Figura 2 pode-se verificar que a variação de apenas $1 \%$ na porcentagem de fécula de batatadoce é responsável por uma variação na viscosidade mais significativa do que a observada com o prolongamento do tratamento térmico. Pode-se observar também a grande variação entre as viscosidades de iogurtes de diferentes marcas comerciais. Verifica-se que a adição da fécula de batata-doce foi eficaz no aumento da viscosidade do permeado.

Como o substrato composto pela mistura do permeado de soro e pela fécula de batata-doce será destinado a produção de uma bebida láctea, baseando-se nos dados obtidos a partir da análise dos produtos comerciais, a viscosidade mais indicada deve estar entre 45 e $70 \mathrm{mPa}$.s.

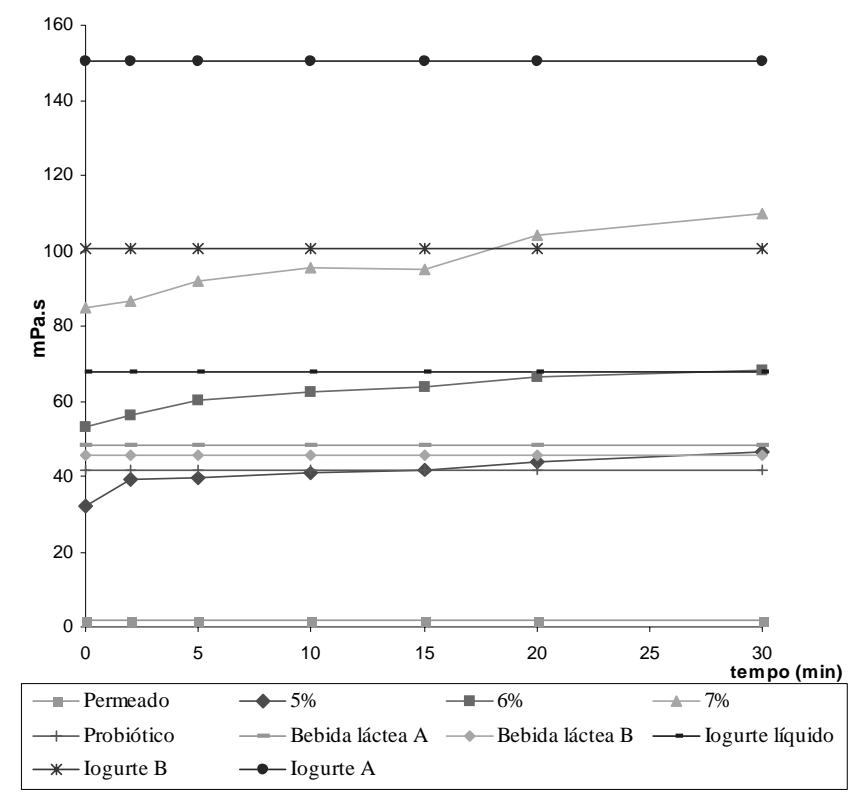

FIGURA 2. Viscosidade das misturas com diferentes porcentagens de fécula de batata-doce e tratamentos térmicos e de alguns produtos comerciais.

\section{5 - Classificação do fluido}

As características reológicas da mistura do permeado de soro de queijo com $6 \%$ de fécula de batata-doce e tratamento térmico de 5 minutos a $90^{\circ} \mathrm{C}$ são apresentadas em maior detalhe na Figura 3. O fluido apresentou um indice de comportamento do escoamento, $n=0,551$ e um índice de consistência, $\mathrm{K}_{\text {ow }}=711,9 \mathrm{mPa} \cdot \mathrm{s}^{\mathrm{n}}$.

A Figura 3 demonstra que o fluido apresentou características de um fluido pseudoplástico, o que era esperado de acordo com o seu valor de $n$.

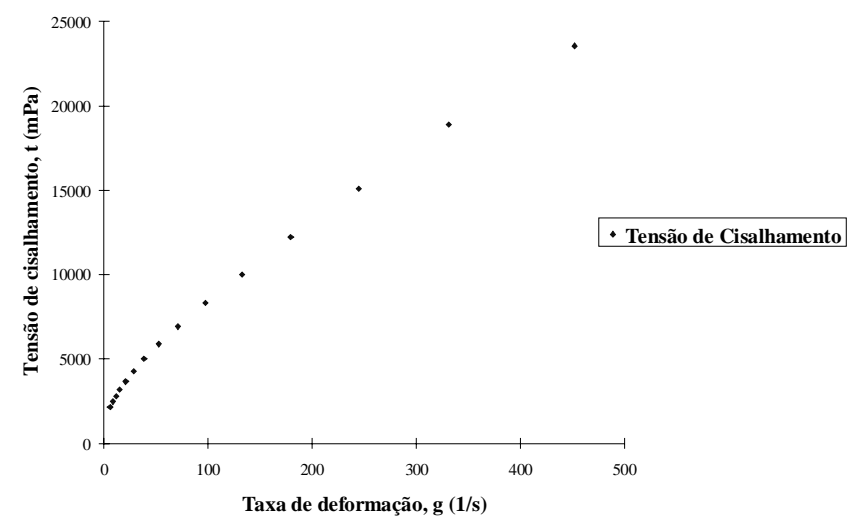

FIGURA 3. Tensão de Cisalhamento $X$ Taxa de deformação

\section{4 - CONCLUSÕES}

A fécula de batata-doce apresentou um bom potencial para o uso como espessante em bebidas lácteas. Devido ao percentual de amido pré-gelatinizado e baixo teor de lipídeos, a fécula é de fácil dissolução no meio utilizado. As proteínas de alta qualidade e a grande quantidade de fibras dietéticas, elevaram o valor nutricional do substrato.

A formulação contendo $6 \%$ de fécula de batata-doce é a que se mantém por mais tempo dentro da faixa de viscosidade desejada para o produto (entre 45 a $70 \mathrm{mPa} . \mathrm{s}$ ). O tempo do tratamento térmico não deve tornar o produto economicamente inviável, mas deve ser suficiente para garantir a sua estabilidade. Assim sendo, o tratamento térmico de 5 minutos mostrou-se o mais adequado.

\section{5 - REFERÊNCIAS BIBLIOGRÁFICAS}

[1] AACC - American Association of Cereal Chemists. Approved Methods. St. Paul, Minnesota, 9 ${ }^{\text {th }}$ ed, 1996.

[2] AOAC - Association of Official Analytical Chemists. Official Methods of the Analysis. 16 ed., Washington. s.n., 1998.

[3] BOBBIO, P. A., BOBBIO, F. O. Manual de Laboratório para Química de Alimentos, Livraria Varela, São Paulo, $1^{\text {a }} \mathrm{ed}$, p. 67-69, 1995.

[4] BOBBIO, P. A., BOBBIO, F. O. Química do Processamento de Alimentos, Livraria Varela, São Paulo, $2^{\text {a }}$ ed, p. 105, 1992.

[5] CEREDA, M.P.; WOSIACK, G.; CONCEIÇÃO, F.A.D. Avaliação físico-química e reológica de vinte e seis cultivares de batata-doce (Ipomoea batatas). Horticultura Brasileira. v. 2, n. 1, p. 6-12, 1984. 
[6] COLLADO, L.S.; MABESA, L.B.; CORKE, H.. Genetic variation in color of sweetpotato flour related to its use in wheatbased composite flour products. Cereal Chemistry. v. 74 , n. 5, p. 681-686, 1997.

[7] COLLINS, J.L.; EBAH, C.B.; MOUNT, J.R.; DRAUGHON, F.A. \& DEMOTT, B.J. Production and evaluation of milk-sweet potato mixtures fermented with yogurt bacteria. Journal of Food Science. v. 56, n. 3, p. 685-688, 1991.

[8] FOX, R.W.; McDONALD, A.T.. Introdução à Mecânica dos Fluidos. Editora Guanabara Koogan S.A, Rio de Janeiro, $4^{\text {a }}$ ed. 1995.

[9] GUEDES, J.M.. Estados Unidos querem aumentar exportação de derivados de leite para o Brasil. Revista Engenharia de Alimentos. RPA Editorial LTDA. Ano 4. n. 20, p. 7-10, 1998.

[10] GURAYA, H.S. \& TOLEDO, R.T. Determining gelatinized starch in a dry starchy product. Journal of Food Science. v. 58, n. 4, p. 888-889, 1993.

[11] HAYES, S. New ways with whey. Nutrition and Food Science, Nov/Dec. p. 5-7, 1985.

[12] HOBMAN, P.G. Review of processes and products for utilization of lactose in deproteinated milk serum. Journal of Dairy Science. v. 67, n. 11, p. 2630-2651, 1984.

[13] KOSIKOWSKI, F.V. Whey utilization and whey products. Journal of Dairy Science. v. 62, n. 7, p. 1149-1159, 1979.

[14] KRISCHKE, W.; SCHRÖDER, M.; TRÖSCH, W. Continuous production of L-lactic acid from whey permeate by immobilized Lactobacillus casei subsp. casei. Applied Microbiology Biotechnology. n. 34, p. 573-578, 1991.

[15] LEONEL, M.; JACKEY, S.; CEREDA, M.P. Processamento industrial de fécula de mandioca e batata doce - um estudo de caso. Ciência e Tecnologia de Alimentos. Campinas. vol. 18, n. 3, 1998.

[16] MORR, C.V. Whey utilization. Chapter 4. In: Whey and lactose processing. Elsevier Appl. Sci., London, $2^{\text {a }}$ ed. p. 136-141, 1992.

[17] PARENTE, E. \& ZOTTOLA, E.A. Growth of thermophilic starters in whey permeate media. Journal of Dairy Science. v. 74, n. 1, p. 20-27, 1991.

[18] SILVA, P.H. da; et al. Físico-quimica do leite e derivados: métodos analíticos. Juiz de Fora : Oficina de Impressão Gráfica e Editora LTDA. p. 50-52. 1997

[19] SABAA-SRUR, A.; KOBLITZ, Maria G.B.; FREIMAN, L.; OLIVEIRA, V. \& GONCALVES, E. Uso integral do soro de queijo Minas frescal na elaboração de bebida láctea fermentada e sua aceitabilidade. Revista Universidade Rural, Série Ciências Exatas e da Terra. v. 17, n. (1/2), 1996.

[20] VIEIRA, J.M.; SABAA-SRUR, A.U.; SILVA, A.B. \& CARVALHO, J.L. Contribuição à industrialização da batata-doce (Ipomoea batatas, L.) cv Rosinha do Verdum - obtenção de fécula. XV Congresso da Sociedade Brasileira de Ciência e Tecnologia de Alimentos. Anais... Poços de Caldas: SBCTA v. 1, p. 008, 1996.

[21] WONG, N.P.; LaCROIX, D.E., \& McDONOUGH, F.E. Minerals in whey and whey fractions. Journal of Dairy Science. v. 61, n. 12, p. 1700-1703, 1978.

[22] YANG, S.T. \& SILVA, E.M. novel products and new technologies for use of a familiar carbohydrate, milk lactose. Journal of Dairy Science. v. 78, n. 11, p. 2541-2562, 1995.

[23] ZALL, R.R. Whey treatment and utilization. In: Food Processing Waste Management. AVI Publishing Company INC, Westport, Connecticut, 1979. 